\title{
Involvement of the arachidonic acid cytochrome P450 epoxygenase pathway in the proliferation and invasion of human multiple myeloma cells
}

Jing Shao, Hongxiang Wang, Guolin Yuan, Zhichao Chen, Qiubai Li

Cytochrome P450 (CYP) epoxygenases and the metabolites epoxyeicosatrienoic acids (EETs) exert multiple biological effects in various malignancies. We have previously found EETs to be secreted by multiple myeloma (MM) cells and to be involved in MM angiogenesis, but the role of the arachidonic acid cytochrome P450 epoxygenase pathway in the proliferation and mobility of MM cells remains unknown. In the present study, we found that MM cell lines generated detectable levels of 11,12-EET/14,15-EET and that increased levels of EETs were found in the serum of MM patients compared to healthy donors. The addition of exogenous EETs induced significantly enhanced proliferation of MM cells, whereas 17-octadecynoic acid (17-ODYA), an inhibitor of the CYP epoxygenase pathway, inhibited the viability and proliferation of MM cells. Moreover, this inhibitory effect could be successfully reversed by exogenous EETs. 17-ODYA also inhibited the motility of MM cells in a time-dependent manner, with a reduction of the gelatinolytic activity and protein expression of the matrix metalloproteinases (MMP)-2 and MMP-9. These results suggest the CYP epoxygenase pathway to be involved in the proliferation and invasion of MM cells, for which 17-ODYA could be a promising therapeutic drug. 
2 Title

3 Involvement of the arachidonic acid cytochrome P450 epoxygenase pathway in the proliferation

4 and invasion of human multiple myeloma cells

5

6 Authors

7 Jing Shao ${ }^{1,2}$, Hongxiang Wang ${ }^{2}$, Guoling Yuan ${ }^{3}$, Zhichao Chen ${ }^{1}$, Qiubai Li ${ }^{1}$

\section{Affiliations}

$10{ }^{1}$ Institute of Hematology, Union Hospital, Tongji Medical College, Huazhong University of 11 Science and Technology, Wuhan 430022, China.

12 2Department of Hematology, Wuhan Central Hospital, Wuhan 430000, China..

$13{ }^{3}$ Department of Hematology, Xiangyang Central Hospital, the Affiliated Hospital of Hubei 14 University of Arts and Science, Xiangyang 441021, China.

Qiubai Li, Institute of Hematology, Union Hospital, Tongji Medical College, Huazhong University of Science and Technology. 1277 Jiefang Ave., Wuhan 430022, China. Tel. and Fax number: 86-27-8572 6387; email: qiubaili@hust.edu.cn. 


\section{Abstract}

Cytochrome P450 (CYP) epoxygenases and the metabolites epoxyeicosatrienoic acids (EETs) exert multiple biological effects in various malignancies. We have previously found EETs to be secreted by multiple myeloma (MM) cells and to be involved in MM angiogenesis, but the role of the arachidonic acid cytochrome P450 epoxygenase pathway in the proliferation and mobility of MM cells remains unknown. In the present study, we found that MM cell lines generated detectable levels of 11,12-EET/14,15-EET and that increased levels of EETs were found in the serum of MM patients compared to healthy donors. The addition of exogenous EETs induced significantly enhanced proliferation of MM cells, whereas 17-octadecynoic acid (17-ODYA), an inhibitor of the CYP epoxygenase pathway, inhibited the viability and proliferation of MM cells. Moreover, this inhibitory effect could be successfully reversed by exogenous EETs. 17-ODYA also inhibited the motility of MM cells in a time-dependent manner, with a reduction of the gelatinolytic activity and protein expression of the matrix metalloproteinases (MMP)-2 and MMP-9. These results suggest the CYP epoxygenase pathway to be involved in the proliferation and invasion of MM cells, for which 17-ODYA could be a promising therapeutic drug. 
Introduction

61 It is well known that arachidonic acid (AA) is converted to eicosanoid mediators by the cyclooxygenases (COX), lipoxygenases (LOX), and cytochrome P450 (CYP) epoxygenase pathways to generate hundreds of metabolites that have different biological activities and contribute to the pathogenesis of numerous diseases. The changes in the expression level and distribution pattern of enzymes involved in eicosanoid biosynthesis may be especially relevant in carcinogenesis (Koch et al. 2011; Wasilewicz et al. 2010). Multiple myeloma (MM) is an incurable plasma cell malignancy characterized by the accumulation of long-living plasma cells in the bone marrow. Current evidence supports the notion of an association between deranged endogenous fatty acids and MM pathogenesis, while the abnormal fatty acid profile may contribute to cancer-associated inflammation through an abnormal arachidonic acids metabolism (Jurczyszyn et al. 2014; Jurczyszyn et al. 2015). AA metabolism pathways are also involved in the pathogenesis of multiple myeloma (MM). COX-2 overexpression is associated with reduced estimated survival of MM patients and unfavorable prognostic factors such as LDH, age, and $\beta_{2^{-}}$ microglobulin (Cetin et al. 2005). 12-LOX is also detected in MM cells, and the inhibitor Baicalein suppresses the proliferation of MM cells ( $\mathrm{Li}$ et al. 2006). However, the role of the cytochrome P450 epoxygenase pathway in the disease progression of MM remains poorly understood.

Primary metabolic products of CYP epoxygenases include four epoxyeicosatrienoic acid (EET) regioisomers: 5,6-EET, 8,9-EET, 11,12-EET, and 14,15-EET. Upon hydration by soluble epoxide hydrolase (sEH), EETs are converted to more stable and less biologically active 
82

metabolites, dihydroxyeicosatrienoic acids (DHETs) (Capdevila et al. 1992; VanRollins et al. 1993). Although each purified CYP epoxygenase converts arachidonic acid to all four EET regioisomers, the main products in many cases are 11,12-EET and 14,15-EET (Capdevila et al. 2000). Studies have shown that small amounts of 8,9-, 11,12-, and 14,15-EETs are present in the plasma, the liver, and the kidney, with 14,15-EET being the most abundant regioisomer (Karara et al. 1991; Karara et al. 1990). EETs are autocrine and paracrine mediators that function primarily in the cardiovascular and renal system, and play a key role in inflammation and tissue homeostasis in the vascular system (Campbell \& Harder 1999). Recently, there is increasing evidence suggesting potential roles of CYP epoxygenases and EETs in tumors (Chen et al. 2011; Jiang et al. 2005; Nithipatikom et al. 2010). EETs dramatically enhance the proliferation and motility of tumor cells, and overexpression of CYP epoxygenases has the same effects in tumor cells in vitro and in vivo.

We previously demonstrated that MM cells secrete EETs into the supernatant and that the CYP epoxygenase pathway participates in the MM cell-induced angiogenesis, which can be inhibited by 17-octadecynoic acid (17-ODYA), an inhibitor of CYP epoxygenase pathway (Shao et al. 2011). In this study, we further investigated the role of the CYP epoxygenase pathway in cell proliferation, apoptosis, migration and invasion of MM.

\section{Materials and Methods}

Materials. Cell culture medium (RPMI 1640 medium) and fetal bovine serum (FBS) were purchased from Invitrogen (Carlsbad, CA, USA). The ELISA kits for 11,12-EET and 14,15-EET were obtained from Detroit R\&D (Detroit, MI, USA). 11,12-EET, 14,15-EET, and 17-ODYA were purchased from Cayman Chemical (Ann Arbor, MI, USA). 3-(4, 5-dimethyl-2-thiazy1)2,5-diphenyl-2H-tetrazolium bromide (MTT) and DMSO were obtained from Sigma Chemical Co. (St. Louis, MO, USA). PI and Annexin V/FITC detection kits were purchased from Bender Medsystems Inc. (Burlingame, CA, USA). Antibodies against CyclinD1, Bax, Bcl-2, MMP-2, 
109

110

111

112

113

114

115

116

117

118

119

120

121

122

123

124

125

126

127

128

129

130

131

132

133

134

135

and MMP-9 were purchased from Epitomics Inc. (Burlingame, CA, USA). Horseradish peroxidase (HRP)-conjugated secondary antibodies (goat-anti-rabbit IgG) were purchased from KPL (Gaithersburg, MA, USA). Enhanced chemiluminescence reagents were purchased from Pierce, Inc. (Rockford, IL, USA). The Transwell plates were obtained from Corning Costar (Cambridge, MA, USA), and the Matrigel was purchased from BD Biosciences (Bedford, MA, USA).

Patient samples. The human study was approved by the Institutional Review Board (Review Board of Tongji Medical College, Huazhong University of Science and Technology, No 2012S119). Sixteen patients diagnosed with MM were selected for the present study after providing informed consent. Three healthy subjects were recruited as controls. Six ml of peripheral blood was collected from all cases. Serum was isolated from peripheral blood by centrifugation at $2,000 \mathrm{rpm}$ for 10 minutes and was frozen at $-80^{\circ} \mathrm{C}$ for the EET Elisa assay. Twelve patients were men, and 4 patients were women (mean age 51 \pm 10 years, range $34-66$ ).

Fifteen patients were diagnosed as stage $\mathbb{I}$ MM, and 1 patient was stage $\mathbb{I}$. Nine patients were group A, and 7 were group B. Eight patients were newly diagnosed, and 3 patients were relapse cases (Table 1).

Cell lines and cell culture. Multiple myeloma cell lines U266 and RPMI8226 were obtained from the American Type Culture Collection (ATCC, Rockville, MD, USA). U266 and RPMI 8226 cells were cultured in RPMI 1640 medium with 10\% fetal bovine serum (FBS), 100 units $/ \mathrm{ml}$ penicillin and $100 \mu \mathrm{g} / \mathrm{ml}$ streptomycin at $37^{\circ} \mathrm{C}$ in a humidified $95 \%$ air/ $5 \% \mathrm{CO}_{2}$ atmosphere incubator.

EET ELISA. For the measurement of EETs in MM cells, cells $\left(1 \times 10^{6} / \mathrm{ml}\right)$ were plated in 6well plates in the presence or absence of 17-ODYA $(100 \mu \mathrm{mol} / \mathrm{L})$. Cells were collected by centrifugation at 2,000 rpm for 10 minutes. EETs in the MM cells and serum of multiple 
136

137

138

139

140

141

142

143

144

145

146

147

148

149

150

151

152

153

154

155

156

157

158

159

160

161

162

myeloma patients were determined using an ELISA kit according to the manufacturer's instructions.

Cell viability and proliferation assays. MM cells were synchronized by incubation in FBSfree RPMI 1640 overnight. 11,12-EET, 14,15-EET and 17-ODYA were added at various concentrations to the media. The cells were cultured for 24,48 or 72 hours. Because of the instability of EETs, they were added to the media every 4-6 hours. DMSO was used as a vehicle for all compounds. After treatment with MTT (20 $\mu$ per well) for 4 hours, DMSO was added to dissolve the crystalline reaction products. The plates were read at a wavelength of $490 \mathrm{~nm}$. Each group measurement was repeated in five duplicate wells.

Determination of cell apoptosis and cell cycle by flow cytometry. Cells were synchronized by incubation in FBS-free RPMI 1640 overnight. These cells $\left(1 \times 10^{6}\right)$ were plated in 6-well plates and treated with 17-ODYA at $100 \mu \mathrm{mol} / \mathrm{L}$ for 48 hours. Subsequently, the cells were harvested and incubated with FITC-conjugated Annexin V and propidium iodide, according to the manufacturer's protocol, and analyzed using a flow cytometer (FACScan, Becton Dickinson, USA).

To analyze the cell cycle distribution, cells $\left(1 \times 10^{6}\right)$ were cultured with 17-ODYA (100 $\mu \mathrm{mol} / \mathrm{L})$ for 48 hours. Thereafter, the cells were harvested and fixed with $75 \%$ ethanol at $-20^{\circ} \mathrm{C}$ overnight. After removing the ethanol, the cells were incubated with RNase $(250 \mu \mathrm{g} / \mathrm{ml})$ at $37^{\circ} \mathrm{C}$ for 30 minutes followed by propidium iodide $(50 \mu \mathrm{g} / \mathrm{ml})$ at $4^{\circ} \mathrm{C}$ for 30 minutes. Cell cycle analysis was determined by flow cytometry.

Western blotting. Proteins from the cell lysates were separated by SDS-PAGE electrophoresis and transferred to a nitrocellulose filter membrane. The membrane was blocked with 5\% nonfat milk and incubated with an antibody against a specific protein antigen. The location of the antibody-antigen complex on the Western blot was revealed by incubation with a 
peroxidase-conjugated secondary antibody. The bands were visualized using the enhanced chemiluminescence method.

Migration assay. Migration assays were conducted as previously described in detail (Fuchida et al. 2008). Briefly, the assay was performed using a 24-well Transwell plates with a polycarbonate membrane with a pore size of $8 \mu \mathrm{m}$. Before the migration assay, cells were treated with 17-ODYA (100 $\mu \mathrm{mol} / \mathrm{L})$ for 24 or 48 hours. The cells were centrifuged and suspended in serum-free RPMI 1640 at a density of $1 \times 10^{6} / \mathrm{ml}$. Volumes of $1 \times 10^{5}$ cells were seeded into the upper chambers, and other cells were cultured concurrently in the mother liquor to calculate the migration ratio. The lower chamber contained RPMI 1640 with $10 \%$ FBS as a chemoattractant. After 24 hours of incubation at $37^{\circ} \mathrm{C}$, the numbers of cells transmigrating into the lower chamber and in the mother liquor were counted using a flow cytometer (FACScan) gated for $20 \mathrm{~s}$ at a high flow rate. The experiments were performed in triplicate. The migration ratio was calculated as the migrated cells as the percentage of cells in the mother liquor.

Invasion assay. The invasion assay was performed as the migration assay, except for the fact that the upper surface of the polycarbonate membranes was coated with Matrigel and dried overnight at $37^{\circ} \mathrm{C}$. The Transwell plates were incubated at $37^{\circ} \mathrm{C}$ for 24 or 48 hours. The cell number was counted by flow cytometry. The invasion ratio was calculated as the migrated cells as the percentage of cells in the mother liquor.

Gelatin zymography. Gelatin zymography was performed using the supernatant of cultured MM cells to evaluate the activity of secreted MMP-2 and MMP-9. Volumes of $1 \times 10^{6}$ cells were incubated with or without 17-ODYA $(100 \mu \mathrm{mol} / \mathrm{L})$ for 24 hours. The culture supernatants were collected and centrifuged at 2000rpm for 10 minutes. Supernatants containing the same amount of proteins from each group were applied to $10 \%$ SDS-PAGE (containing $0.1 \%$ gelatin). After electrophoresis, the gels were washed in $2.5 \%$ Triton X-100 for 80 minutes to remove SDS. The 
190

191

192

193

194

195

196

197

198

199

200

201

202

203

204

205

206

207

208

209

210

211

212

213

214

215

216

gels were incubated for 20 hours at $37^{\circ} \mathrm{C}$ and stained with $0.5 \%$ Coomassie brilliant blue for 3 hours. After staining, the gels were destained with 30\% methanol and $10 \%$ acetic acid.

Statistics. The data are presented as the mean \pm SE. All experiments were done with triplicate replications of each treatment group $(n=3)$. Student's t test or ANOVA was performed as appropriate to determine the statistical significance of differences among different groups. The Mann-Whitney two-sample test was used to investigate the significant differences of EET concentration between MM patients and healthy controls. Correlation analysis was used to examine the correlation between sets of variables in MM patients. In all cases, statistical significance was defined by $P<0.05$.

\section{Results}

\section{EETs in MM cell lines and the peripheral blood serum of MM patients}

We previously found secreted 11,12-EET and 14,15-EET in the supernatant of MM cell lines (Shao et al. 2011), but the expression levels of 11,12-EET and 14,15-EET in MM cells is unknown. Therefore, we directly assessed the levels of these EETs in MM cells. Based upon the results of EET ELISA assay, we found both MM cell lines U266 and RPMI 8226 produced 11,12-EET and 14,15-EET (Figure 1A). The levels of 14,15-EET were much higher than those of 11,12-EET in the two cell lines, suggesting that 14,15-EET was the most abundant regioisomer (Karara et al. 1991; Karara et al. 1990). We also evaluated the levels of EETs in MM patients after collecting the peripheral blood serum of 16 patients and 3 healthy volunteers, as shown in Table 1. The results showed that the concentrations of 11,12-EET and 14,15-EET were significantly higher in patients than in healthy donors (Figure 1B). The mean concentration of 11,12 -EET in patient serum was $291.94 \pm 383.98 \mathrm{ng} / \mathrm{ml}$ (range from 0.78 to $1,193.36 \mathrm{ng} / \mathrm{ml}$ ), which was significantly different from the control $(5.10 \pm 2.31 \mathrm{ng} / \mathrm{ml}$, range from 2.86 to 7.47 $\mathrm{ng} / \mathrm{ml}),(P<0.01)$. The mean concentration of 14,15-EET in MM serum was 1,056.48 \pm 906.47 $\mathrm{ng} / \mathrm{ml}$ (range from 0.61 to $2,754.99 \mathrm{ng} / \mathrm{ml}$ ), which was markedly higher than the control with 
$2174.92 \pm 2.32 \mathrm{ng} / \mathrm{ml}$ (range from 2.54 to $7.18 \mathrm{ng} / \mathrm{ml})(P<0.01)$. Meanwhile, we analyzed the 218 correlations of EET concentrations with the prognostic factors, such as LDH and $\beta 2$ 219 microglobulin, but no statistically significant correlation was found. With regard to LDH and $\beta 2-$ 220 microglobulin, the results for 11,12 -EET were $\mathrm{r}=-0.139, P>0.05$ and $\mathrm{r}=-0.27, P>0.05$, respectively, and for $14,15-\mathrm{EET}, \mathrm{r}=-0.395, P>0.05$ and $\mathrm{r}=-0.114, P>0.05$, respectively.

222

\section{7-ODYA suppressed EET levels and the proliferation of MM cells}

Based on previous studies (Chen et al. 2011; Jiang et al. 2005; Nithipatikom et al. 2010) and our above results, we hypothesized that EETs may contribute to the neoplastic phenotype of MM. First, we determined the effect of exogenous EETs on the proliferation of MM cells and found that concentrations of 11,12-EET and 14,15-EET in the range of $100 \mathrm{nmol} / \mathrm{L}$ to $400 \mathrm{nmol} / \mathrm{L}$ increased the proliferation of U266 and RPMI 8226 cells in vitro for 24, 48 and 72 hours (Figure 2A). These EEts also promoted cell viability in a dose and time dependent-manners. Because of the instability of EETs, they should be added to the medium every 4-6 hours, but the vehicle (DMSO) significantly affected the viability of the cells (Fig.S1). Thus, we analyzed the differences between the vehicle and experimental groups. As 17-ODYA is the inhibitor of CYP epoxygenases, we measured the levels of EETs in MM cells in the presence or absence of 17ODYA to further characterize the effect of 17-ODYA on the biosynthesis of eicosanoids in MM cells. Our findings revealed that 17-ODYA decreased both the levels of 11,12-EET and 14,15EET in U266 and RPMI 8226 cells (Figure 2B). Meanwhile, the addition of the epoxygenase inhibitor 17-ODYA decreased the proliferation of MM cells, and the inhibition ratio increased with the dose and duration of treatment (Figure 2C). Importantly, exogenous EETs reversed the 17-ODYA-mediated decrease in proliferation of the MM cell lines compared to the vehicle (DMSO) group (Figure 2D). These results indicate that CYP epoxygenase-derived EETs promote the viability of MM cells and that CYP epoxygenases may play an important role in the 242 proliferation of multiple myeloma. 
244

245

246

247

248

249

250

251

252

253

254

255

256

257

258

259

260

261

262

263

264

265

266

267

268

269

270

\section{7-ODYA induced apoptosis and cell cycle arrest of MM cells}

We next investigated whether 17-ODYA induced cellular apoptosis or disrupted the cell cycle. After treatment with 17-ODYA for 48 hours, the ratios of apoptotic cells were assessed using Annexin V/PI staining. Treatment of both U266 and RPMI 8226 cells with $100 \mu \mathrm{mol} / \mathrm{L} 17$ ODYA increased apoptosis compared with control (blank) group $(P<0.05$; Figure 3A). Treatment with 17-ODYA $(100 \mu \mathrm{mol} / \mathrm{L})$ for 48 hours also increased the percentage of cells in $\mathrm{G}_{0} / \mathrm{G}_{1}$ phase in both MM cell lines compared to the control (blank) and vehicle (DMSO) group $(P<0.05$; Figure3B). We next measured apoptosis and cell cycle-related proteins by Western blot analysis, and the results revealed that treatment with 17-ODYA decreased the levels of the $\mathrm{G}_{1}$ phase regulatory protein cyclin D1 and antiapoptotic protein Bcl-2, while increasing the level of proapoptotic protein Bax (Figure 4). Collectively, these results suggest that the epoxygenase pathway is possibly involved in enhancing the proliferation of myeloma cells by protecting cells from apoptosis and promoting the cell cycle progression.

\section{7-ODYA inhibited the motility of MM cells}

Migration and invasion of MM cells were evaluated using a Transwell model in vitro. 17-ODYA significantly decreased cell migration of both MM cell lines, and the migration ratio decreased in a time-dependent manner (Figure 5A). The migration ratio of 17-ODYA treatment for $24 \mathrm{~h}$ was $0.93 \pm 0.07 \%$ compared to $1.37 \pm 0.13 \%$ for the control (blank) group $(P<0.05)$, and $0.10 \pm$ $0.02 \%$ for the $48 \mathrm{~h}$ group compared with the control (blank) group $(P<0.05)$ in U266 cells. The results of RPMI 8226 cells were $1.07 \pm 0.36 \%$ for the $24 \mathrm{~h}$ group and $0.48 \pm 0.04 \%$ for the $48 \mathrm{~h}$ group compared to $1.57 \pm 0.06 \%$ for the control (blank) group $(P<0.05)$. 17-ODYA also inhibited the invasion of MM cells (Figure 5B). As MMPs play an important role in tumor metastasis, we used gelatin zymography assays and Western blotting to investigate the activity and protein content of MMPs in MM cells. As shown in Figure 5C, 17-ODYA treatment suppressed the activity of MMPs in the supernatant. To investigate whether the 17-ODYAinduced inhibition of MMP-2 and MMP-9 activity was caused by changes in the protein levels, 
271 MM cells were also analyzed by Western blot. The results showed that the levels of MMP-2 and 272 MMP-9 were decreased by 17-ODYA treatment in both MM cell lines (Figure 5D). Altogether, 273 the inhibitor 17-ODYA suppressed the motility of MM cells and reduced the activity and protein 274 levels of secreted MMPs.

\section{Discussion}

As the main products of CYP epoxygenases in many MM cases are 11,12-EET and 14,15-EET

(Capdevila et al. 2000), we measured these two EETs in MM cells and in the serum of MM patients. In the present study, we found that both MM cell lines (U266, RPMI 8226) produced different levels of 11,12-EET and 14,15-EET and that EETs were also detected in high concentrations in the serum of MM patients. Accordingly, in leukemia and lymphoma, two other hematological malignancies, high levels of EETs in the urine and blood of patients compared to the healthy controls were reported by Chen et al. (Chen et al. 2011). These findings indicate that high levels of the EETs are one of the pathological characteristics of hematological malignancies, including MM. The clinical role of EETs in MM stratification and prognosis is to be determined in future studies.

EETs are the major biologically active metabolites of CYP epoxygenases and are locally active small molecule lipid mediators that play a central role in various cellular functions, including proliferation, migration and angiogenesis (Chen et al. 2001; Enayetallah et al. 2006; Jiang et al. 2005; Michaelis et al. 2005; Node et al. 1999; Wei et al. 2014). In this study, we found that both 11,12-EET and 14,15-EET significantly promoted the proliferation of MM cells, while the inhibitor 17-ODYA suppressed EET levels and the viability of all tested MM cells in a dose- and time-dependent manner. Additionally, the 17-ODYA-mediated decrease of proliferation was reversed by exogenous EETs. These findings support the notion that the elevation of EETs promotes the viability of MM cells. To be noted, 17-ODYA is also considered as an inhibitor of cytochrome P-450 omega-hydroxylase (Ohata et al. 2010), but 20-HETE, the product of 
298

299

300

301

302

303

304

305

306

307

cytochrome P-450 omega-hydroxylase, was not considered in the present study. Though the expression and role of 20-HETE is unknown in MM cells, it is important to be further demonstrated using other specific epoxygenase inhibitors, such as MS-PPOH (Wang et al. 1998).

In the present study, 17-ODYA increased the apoptosis and induced cell cycle arrest at the $\mathrm{G}_{0} / \mathrm{G}_{1}$ phase in MM cells, suggesting that 17-ODYA-induced suppression of MM cells proliferation is possibly mediated through the induction of apoptosis and cell cycle arrest. Our results also showed that the $\mathrm{G}_{1}$ phase regulatory protein cyclin $\mathrm{D} 1$ and $\mathrm{Bcl}-2$ antiapoptotic protein were markedly down-regulated by 17-ODYA, along with up-regulation of Bax proapoptotic protein. These proteins have been shown to play a key role in MM pathogenesis (Marsaud et al. 2010). Thus, together with our previous findings about EET-induced angiogenesis in MM, the present study supported the hypothesis that EETs and CYP epoxygenase pathway contribute to the neoplastic phenotype of MM cells.

Although a prominent feature of MM consists in the localization of MM cells in the bone marrow, a few MM cells can also be detected in the peripheral circulation. These observations suggest that MM cells have the capacity to circulate, invade and home to the bone marrow (Alsayed et al. 2007; Vande Broek et al. 2007). In the end stage of MM, the circulating plasma cells increase and grow at extramedullary sites (Pour et al. 2014). Clearly, the motility of MM cells is related to the disease progression. Numerous evidence has confirmed that EETs induce endothelial cell migration, even enhancing hematopoietic stem and progenitor cell homing and engraftment (Li et al. 2015). The present study showed that 17-ODYA can significantly inhibit, in a time-dependent manner, the motility of MM cells, including the migration and invasion of all tested MM cells. These results demonstrated that the epoxygenase pathway may be involved in the regulation of the motility of MM cells through the metabolites EETs. MM cells can localize in the bone marrow, which consists of extracellular matrix (ECM) and stromal cells, and MM cells have the capacity to invade and constitutively produce MMPs that are essential for 
325

326

327

328

329

330

331

332

333

334

335

336

337

338

339

340

341

342

343

344

345

346

347

348

349

350

351

matrix degradation (Barillé et al. 1997; Hecht et al. 2007; Vande Broek et al. 2004). In the present study, both U266 and RPMI 8226 cells expressed and secreted MMP-2 and MMP-9 proteins that can hydrolyze gelatin, but 17-ODYA reduced the activity of MMPs and suppressed the protein levels of both MMP-2 and MMP-9 in MM cells. These data revealed the role of the epoxygenase pathway in 17-ODYA-mediated inhibition of invasion and MMP protein levels.

Combined with our previous findings (Shao et al. 2011), the present study supports the involvement of the CYP epoxygenase pathway and the elevated levels of EETs in the proliferation, angiogenesis and motility of MM cells. We have identified the role of the third pathway of the arachidonic acid metabolism, the CYP epoxygenase pathway, in the pathogenesis of MM. It is not clear how active MM develops from the "dormancy period" of monoclonal gammopathy of undetermined significance (MGUS). Recently, EETs were found to stimulate tumor cells to escape from tumor dormancy in several tumor models (Panigrahy et al.). Thus, we can reasonably hypothesize that EETs may promote MM to escape from this "dormancy period" and that the CYP epoxygenase pathway may be substantially involved in this progression. In conclusion, the CYP pathway could be an important therapeutic target, and the inhibitor 17ODYA appears to be an attractive candidate for MM therapy.

\section{References}

Alsayed Y, Ngo H, Runnels J, Leleu X, Singha UK, Pitsillides CM, Spencer JA, Kimlinger T, Ghobrial JM, Jia X, Lu G, Timm M, Kumar A, Côté D, Veilleux I, Hedin KE, Roodman GD, Witzig TE, Kung AL, Hideshima T, Anderson KC, Lin CP, and Ghobrial IM. 2007. Mechanisms of regulation of CXCR4/SDF-1 (CXCL12)-dependent migration and homing in multiple myeloma. Blood 109:27082717. 10.1182/blood-2006-07-035857

Barillé S, Akhoundi C, Collette M, Mellerin M-P, Rapp M-J, Harousseau J-L, Bataille R, and Amiot M. 1997. Metalloproteinases in Multiple Myeloma: Production of Matrix Metalloproteinase-9 (MMP-9), 
352

353

354

355

356

357

358

359

360

361

362

363

364

365

366

367

368

369

370

371

372

373

374

375

376

377

378

Activation of proMMP-2, and Induction of MMP-1 by Myeloma Cells. Blood 90:1649-1655.

Campbell WB, and Harder DR. 1999. Endothelium-Derived Hyperpolarizing Factors and Vascular Cytochrome P450 Metabolites of Arachidonic Acid in the Regulation of Tone. Circulation Research 84:484-488. 10.1161/01.res.84.4.484

Capdevila JH, Falck JR, and Harris RC. 2000. Cytochrome P450 and arachidonic acid bioactivation: molecular and functional properties of the arachidonate monooxygenase. Journal of Lipid Research 41:163-181.

Capdevila JH, Wei S, Yan J, Karara A, Jacobson HR, Falck JR, Guengerich FP, and DuBois RN. 1992. Cytochrome P-450 arachidonic acid epoxygenase. Regulatory control of the renal epoxygenase by dietary salt loading. Journal of Biological Chemistry 267:21720-21726.

Cetin M, Buyukberber S, Demir M, Sari I, Sari I, Deniz K, Eser B, Altuntas F, Camc1 C, Öztürk A, Turgut B, Vural Ö, and Unal A. 2005. Overexpression of cyclooxygenase-2 in multiple myeloma: Association with reduced survival. American Journal of Hematology 80:169-173. 10.1002/ajh.20460

Chen C, Wei X, Rao X, Wu J, Yang S, Chen F, Ma D, Zhou J, Dackor RT, Zeldin DC, and Wang DW. 2011. Cytochrome P450 2J2 Is Highly Expressed in Hematologic Malignant Diseases and Promotes Tumor Cell Growth. Journal of Pharmacology and Experimental Therapeutics 336:344-355. 10.1124/jpet.110.174805

Chen J-K, Capdevila J, and Harris RC. 2001. Cytochrome P450 Epoxygenase Metabolism of Arachidonic Acid Inhibits Apoptosis. Molecular and Cellular Biology 21:6322-6331. 10.1128/mcb.21.18.63226331.2001

Enayetallah AE, French RA, and Grant DF. 2006. Distribution of soluble epoxide hydrolase, cytochrome P450 2C8, 2C9 and 2J2 in human malignant neoplasms. Journal of Molecular Histology 37:133-141. $10.1007 / \mathrm{s} 10735-006-9050-9$

Fuchida SI, Shimazaki C, Hirai H, Akamatsu S, Yamada N, Uchida R, Okano A, Okamoto M, Inaba T, and Taniwaki M. 2008. The effects of thalidomide on chemotactic migration of multiple myeloma cell lines. International Journal of Laboratory Hematology 30:220-229. 10.1111/j.1751553X.2007.00948.X

Hecht M, Heider U, Kaiser M, Von Metzler I, Sterz J, and Sezer O. 2007. Osteoblasts promote migration and 
invasion of myeloma cells through upregulation of matrix metalloproteinases, urokinase plasminogen activator, hepatocyte growth factor and activation of p38 MAPK. British Journal Of Haematology $138: 446-458.10 .1111 / \mathrm{j} .1365-2141.2007 .06665 . \mathrm{x}$

Jiang J-G, Chen C-L, Card JW, Yang S, Chen J-X, Fu X-N, Ning Y-G, Xiao X, Zeldin DC, and Wang DW. 2005. Cytochrome P450 2J2 Promotes the Neoplastic Phenotype of Carcinoma Cells and Is Upregulated in Human Tumors. Cancer Research 65:4707-4715. 10.1158/0008-5472.can-04-4173

Jurczyszyn A, Czepiel J, Gdula-Argasińska J, Czapkiewicz A, Biesiada G, Dróżdż M, Perucki W, and Castillo JJ. 2014. Erythrocyte membrane fatty acids in multiple myeloma patients. Leukemia Research 38:1260-1265. http://dx.doi.org/10.1016/j.leukres.2014.08.009

Jurczyszyn A, Czepiel J, Gdula-Argasińska J, Paśko P, Czapkiewicz A, Librowski T, Perucki W, Butrym A, Castillo JJ, and Skotnicki AB. 2015. Plasma fatty acid profile in multiple myeloma patients. Leukemia Research 39:400-405. http://dx.doi.org/10.1016/j.leukres.2014.12.010

Karara A, Dishman E, Falck JR, and Capdevila JH. 1991. Endogenous epoxyeicosatrienoyl-phospholipids. A novel class of cellular glycerolipids containing epoxidized arachidonate moieties. Journal of Biological Chemistry 266:7561-7569.

Karara A, Dishman E, Jacobson H, Falck JR, and Capdevila JH. 1990. Arachidonic acid epoxygenase. Febs Letters 268:227-230. 10.1016/0014-5793(90)81014-f

Koch A, Gustafsson B, Fohlin H, and Sörenson S. 2011. Cyclooxygenase-2 expression in lung cancer cells evaluated by immunocytochemistry. Diagnostic Cytopathology 39:188-193. 10.1002/dc.21366

Li P, Lahvic JL, Binder V, Pugach EK, Riley EB, Tamplin OJ, Panigrahy D, Bowman TV, Barrett FG, Heffner GC, McKinney-Freeman S, Schlaeger TM, Daley GQ, Zeldin DC, and Zon LI. 2015. Epoxyeicosatrienoic acids enhance embryonic haematopoiesis and adult marrow engraftment. Nature 523:468-471. 10.1038/nature 14569

http://www.nature.com/nature/journal/v523/n7561/abs/nature14569.html\#supplementary-information

Li QB, You Y, Chen ZC, Lu J, Shao J, and Zou P. 2006. Role of Baicalein in the regulation of proliferation and apoptosis in human myeloma RPM18226 cells. Chinese Medical Journal 119:948-952.

Marsaud V, Tchakarska G, Andrieux G, Liu J-M, Dembele D, Jost B, Wdzieczak-Bakala J, Renoir J-M, and 
406

407

408

409

410

411

412

413

414

415

416

417

418

419

420

421

422

423

424

Sola B. 2010. Cyclin K and cyclin D1b are oncogenic in myeloma cells. Molecular Cancer 9:1-19. $10.1186 / 1476-4598-9-103$

Michaelis UR, Fisslthaler B, Barbosa-Sicard E, Falck JR, Fleming I, and Busse R. 2005. Cytochrome P450 epoxygenases 2C8 and 2C9 are implicated in hypoxia-induced endothelial cell migration and angiogenesis. Journal of Cell Science 118:5489-5498. 10.1242/jcs.02674

Nithipatikom K, Brody DM, Tang AT, Manthati VL, Falck JR, Williams CL, and Campbell WB. 2010. Inhibition of carcinoma cell motility by epoxyeicosatrienoic acid (EET) antagonists. Cancer Science 101:2629-2636. 10.1111/j.1349-7006.2010.01713.x

Node K, Huo Y, Ruan X, Yang B, Spiecker M, Ley K, Zeldin DC, and Liao JK. 1999. Anti-inflammatory Properties of Cytochrome P450 Epoxygenase-Derived Eicosanoids. Science 285:1276-1279. 10.1126/science. 285.5431 .1276

Ohata H, Gebremedhin D, Narayanan J, Harder DR, and Koehler RC. 2010. Onset of pulmonary ventilation in fetal sheep produces pial arteriolar constriction dependent on cytochrome p450 $\omega$-hydroxylase activity. Journal of Applied Physiology 109:412-417. 10.1152/japplphysiol.01090.2009

Panigrahy D, Edin ML, Lee CR, Huang S, Bielenberg DR, Butterfield CE, Barn, xE, s CM, Mammoto A, Mammoto T, Luria A, Benny O, Chaponis DM, Dudley AC, Greene ER, Vergilio J-A, Pietramaggiori G, Scherer-Pietramaggiori SS, Short SM, Seth M, Lih FB, Tomer KB, Yang J, Schwendener RA, Hammock BD, Falck JR, Manthati VL, Ingber DE, Kaipainen A, x, Amore PA, Kieran MW, and Zeldin DC. Epoxyeicosanoids stimulate multiorgan metastasis and tumor dormancy escape in mice. The Journal of Clinical Investigation 122:178-191. 10.1172/jci58128

Pour L, Sevcikova S, Greslikova H, Kupska R, Majkova P, Zahradova L, Sandecka V, Adam Z, Krejci M, Kuglik P, and Hajek R. 2014. Soft-tissue extramedullary multiple myeloma prognosis is significantly worse in comparison to bone-related extramedullary relapse. Haematologica 99:360-364. 10.3324/haematol.2013.094409

Shao J, Li QB, Wang HX, Liu F, Jiang JG, Zhu XJ, Chen ZC, and Zou P. 2011. P-450-dependent Epoxygenase Pathway of Arachidonic Acid Is Involved in Myeloma-induced Angiogenesis of Endothelial Cells. Journal of Huazhong University of Science and Technology-Medical Sciences 31:596-601. 
Vande Broek I, Asosingh K, Allegaert V, Leleu X, Facon T, Vanderkerken K, Van Camp B, and Van Riet I. 2004. Bone marrow endothelial cells increase the invasiveness of human multiple myeloma cells 
Figure legends

467

Figure 1. Levels of EETs in MM cells and serum of MM patients. 11,12-EET and 14,15-EET levels were determined by ELISA following the instruction of manufacturers. A, MM cell lines $\left(1 \times 10^{6}\right.$ cells $)$ expressed 11, 12-EET and 14, 15-EET. B, 11, 12-EET and 14, 15-EET levels from healthy volunteers and patients with multiple myeloma (the ordinate was for log transformation; EETs in MM patients serum were significantly higher compared with healthy subjects, $P<0.01$ ).

Figure 2. 17-ODYA decreases EETs level in MM cells and suppresses MM cell viability. A, once addition of exogenous 11,12-EET or 14,15-EET increased the viability of U266 and RPMI8226 ( ${ }^{*} P<0.05$ versus DMSO vehicle group). B, 17-ODYA $(100 \mu \mathrm{mol} / \mathrm{L})$ treated U266 and RPMI8226 for $24 \mathrm{~h}$ or $48 \mathrm{~h}$, and Elisa assay was used to detect the 11, 12-EET and 14, 15EET levels in MM cells $\left({ }^{*} P<0.05\right.$ versus control). C, 17-ODYA $(100 \mu \mathrm{mol} / \mathrm{L})$ decreased cell viability of U266 and RPMI8226 in dose and time dependent manners ( ${ }^{*} P<0.05$ versus control). D. 17-ODYA $(100 \mu \mathrm{mol} / \mathrm{L})$ suppressed the proliferation of U266 and RPMI8226 cells, which could be reversed by exogenous EETs (all groups were treated with $100 \mu \mathrm{mol} / \mathrm{L}$ 17-ODYA for 24 hours; ${ }^{*} P<0.05$ versus vehicle group).

Figure 3. Epoxygenase inhibitor 17-ODYA enhances MM cell apoptosis and induces cell arrest at $\mathrm{G}_{0} / \mathrm{G}_{1}$ phase. A, apoptosis of $\mathrm{MM}$ cells was increased by $17-\mathrm{ODY} A(100 \mu \mathrm{mol} / \mathrm{L})$ treatment for 48h $\left({ }^{*} P<0.05\right.$ versus control). B, cell arrest at $\mathrm{G}_{0} / \mathrm{G}_{1}$ phase was induced by 17-ODYA 
$487(100 \mu \mathrm{mol} / \mathrm{L})$ treatment for $48 \mathrm{~h}\left({ }^{*} P<0.05\right.$ versus control $)$.

488

Figure 4. Effect of 17-ODYA on levels of Bax, Bcl-2 and cyclin D1 protein in MM. Treatment

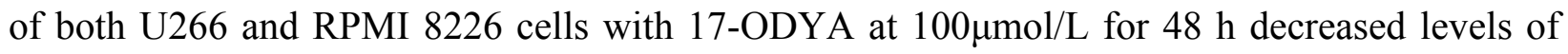
cyclin $\mathrm{D} 1$, the $\mathrm{G}_{1}$ phase regulatory protein, and antiapoptotic protein $\mathrm{Bcl}-2$, while increased the level of Bax, a proapoptotic protein.

493

Figure 5. 17-ODYA inhibits MM cell mobility through reducing MMP activity and protein levels. MM cells were treated by $17-O D Y A(100 \mu \mathrm{mol} / \mathrm{L})$ for $24 \mathrm{~h}$ or $48 \mathrm{~h}$, and DMSO was used 496 for the vehicle. A, 17-ODYA inhibited the migration of MM cells $\left({ }^{*} P>0.05\right.$ versus control; ${ }^{* *} P$ $497<0.05$ versus control). B, 17-ODYA inhibited the invasion of MM cells $\left({ }^{*} P>0.05\right.$ versus 498 control; ${ }^{* *} P<0.05$ versus control). C, 17-ODYA reduced MMPs activity in the supernatant of 499 MM cells $\left({ }^{*} P<0.05\right.$ versus control). D, 17-ODYA reduced MMPs protein level in MM cells $\left({ }^{*} P\right.$ $500<0.05$ versus control) 


\section{1}

Levels of EETs in MM cells and serum of MM patients.

11,12-EET and 14,15-EET levels were determined by ELISA following the instruction of manufacturers. A, MM cell lines ( $1 \times 10^{6}$ cells) expressed 11, 12-EET and 14, 15-EET. B, 11, 12EET and 14, 15-EET levels from healthy volunteers and patients with multiple myeloma (the ordinate was for log transformation; EETs in MM patients serum were significantly higher compared with healthy subjects, $P<0.01$ ).

$\mathbf{A}$
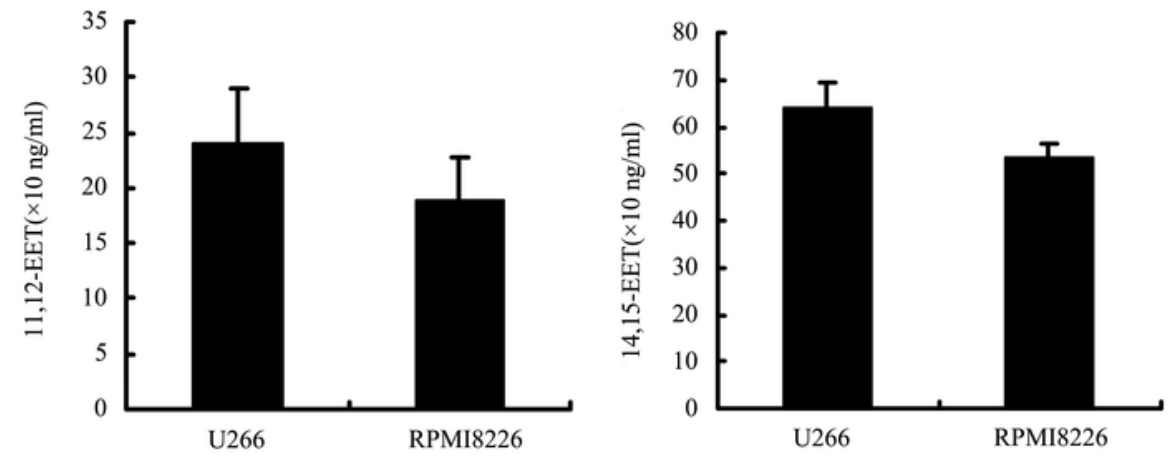

B
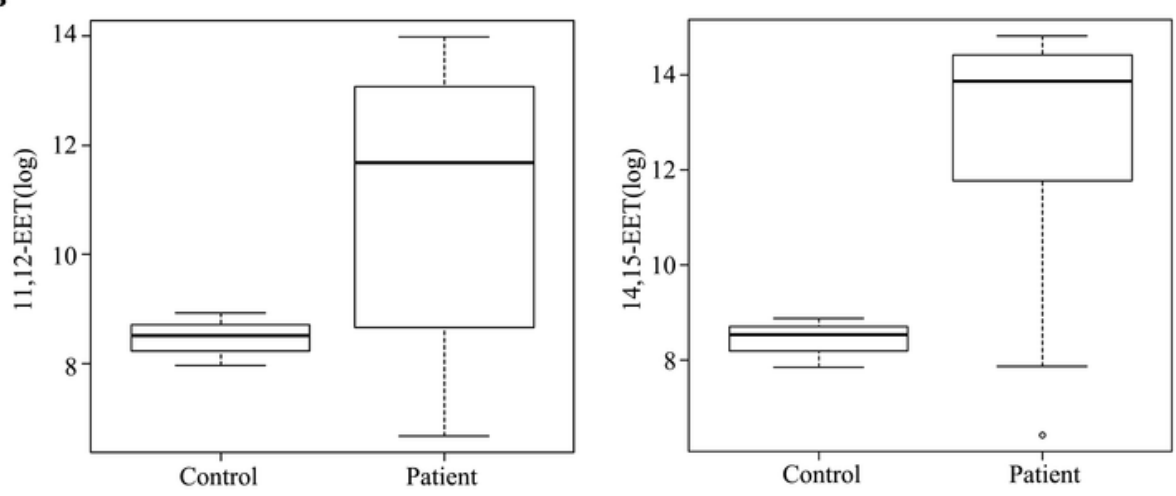
2

17-ODYA decreases EETs level in MM cells and suppresses MM cell viability.

A, once addition of exogenous 11,12 -EET or 14,15-EET increased the viability of U266 and RPMI8226 ( ${ }^{*} P<0.05$ versus DMSO vehicle group). B, 17-ODYA (100 $\left.\mu \mathrm{mol} / \mathrm{L}\right)$ treated U266 and RPMI8226 for $24 \mathrm{~h}$ or $48 \mathrm{~h}$, and Elisa assay was used to detect the 11, 12-EET and 14, 15-EET levels in MM cells ( ${ }^{*} P<0.05$ versus control). C, 17-ODYA (100 $\left.\mathrm{mmol} / \mathrm{L}\right)$ decreased cell viability of U266 and RPMI8226 in dose and time dependent manners ( ${ }^{*} P<0.05$ versus control). D. 17-

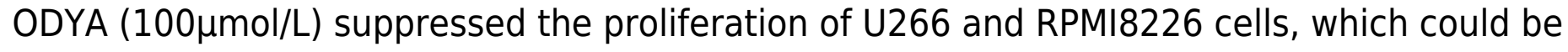
reversed by exogenous EETs (all groups were treated with $100 \mu \mathrm{mol} / \mathrm{L}$ 17-ODYA for 24 hours; ${ }^{*} P<0.05$ versus vehicle group).
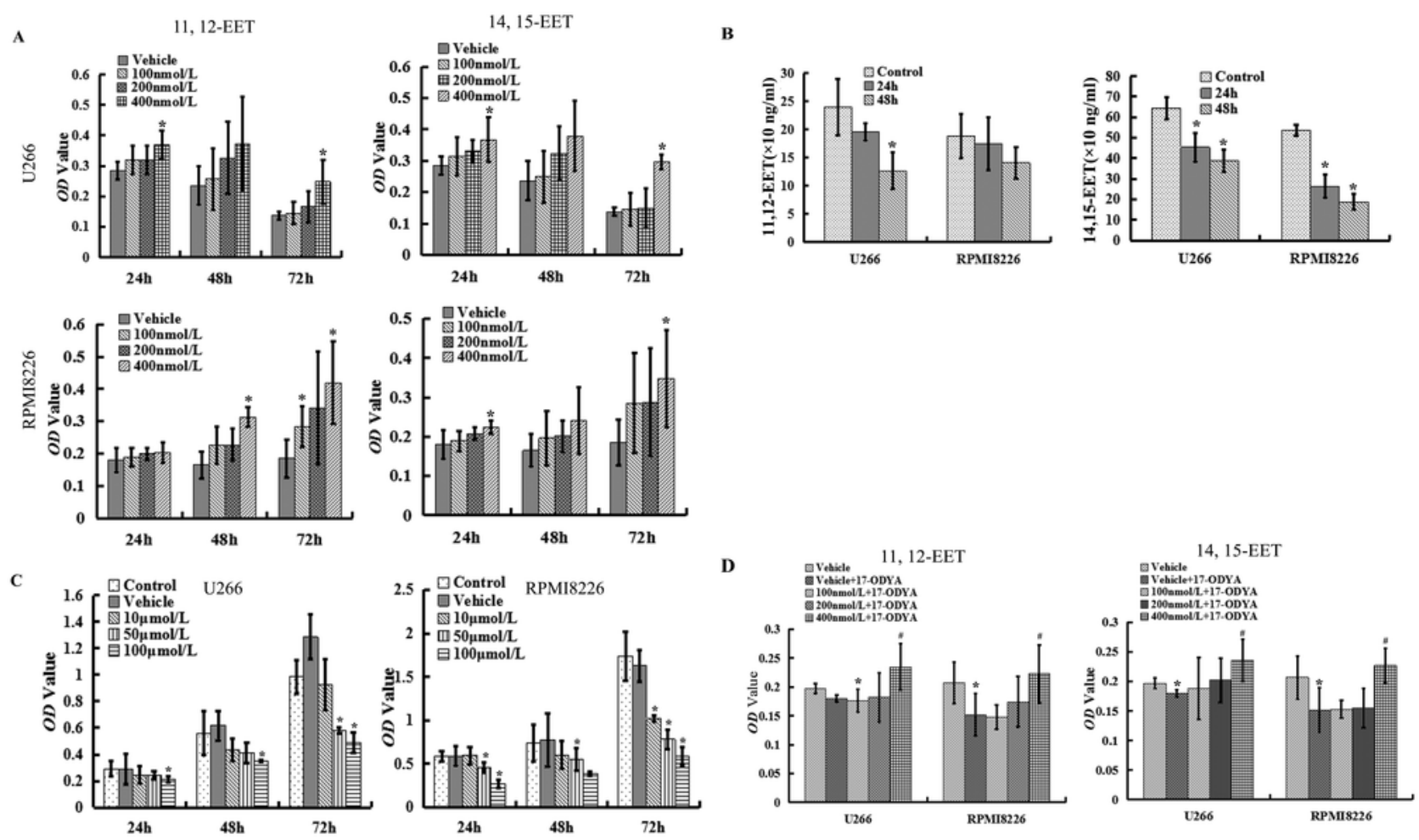
3

Epoxygenase inhibitor 17-ODYA enhances MM cell apoptosis and induces cell arrest at $\mathrm{G}_{0} / \mathrm{G}_{1}$ phase.

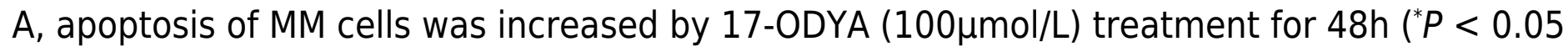
versus control). B, cell arrest at $\mathrm{G}_{0} / \mathrm{G}_{1}$ phase was induced by $17-\mathrm{ODYA}(100 \mu \mathrm{mol} / \mathrm{L})$ treatment for $48 \mathrm{~h}\left({ }^{*} P<0.05\right.$ versus control).

$\mathbf{A}$
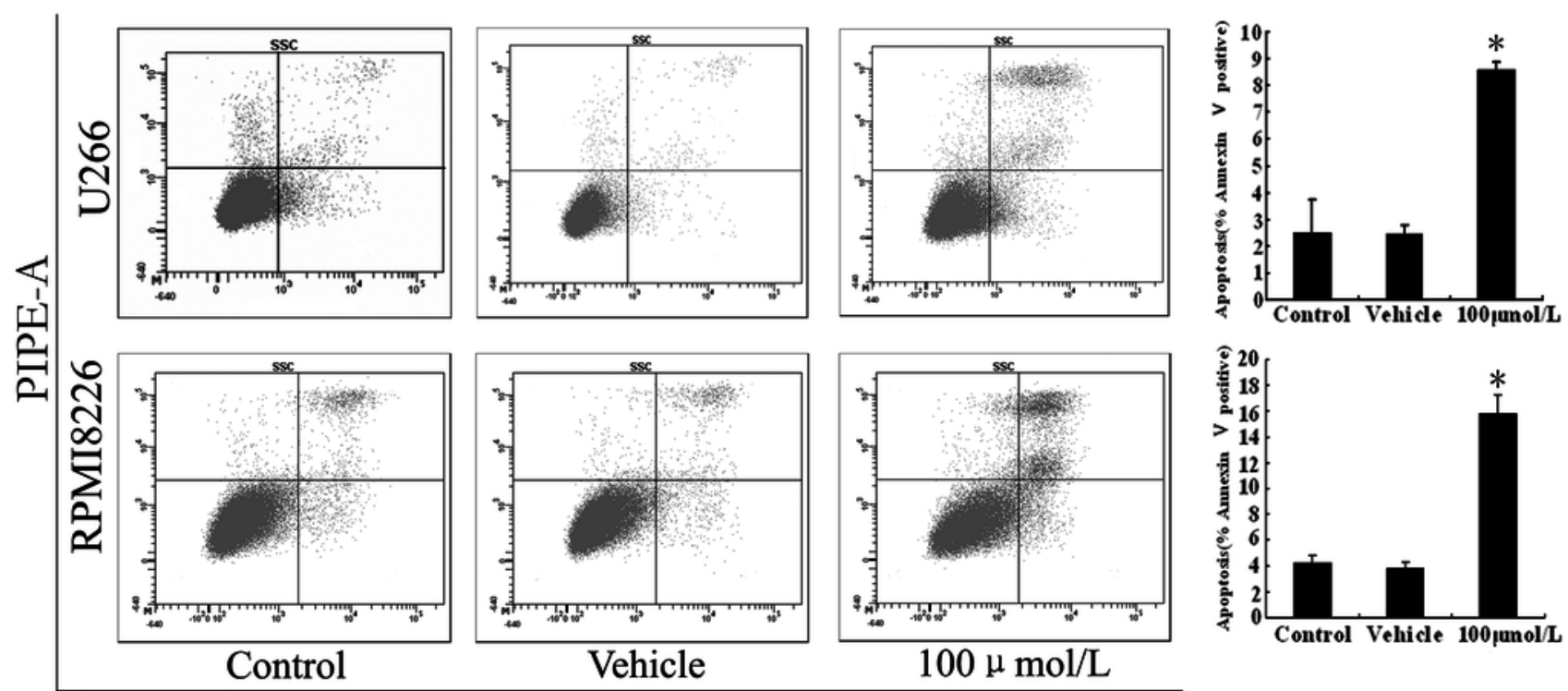

B

ANNEXIN FITC-A
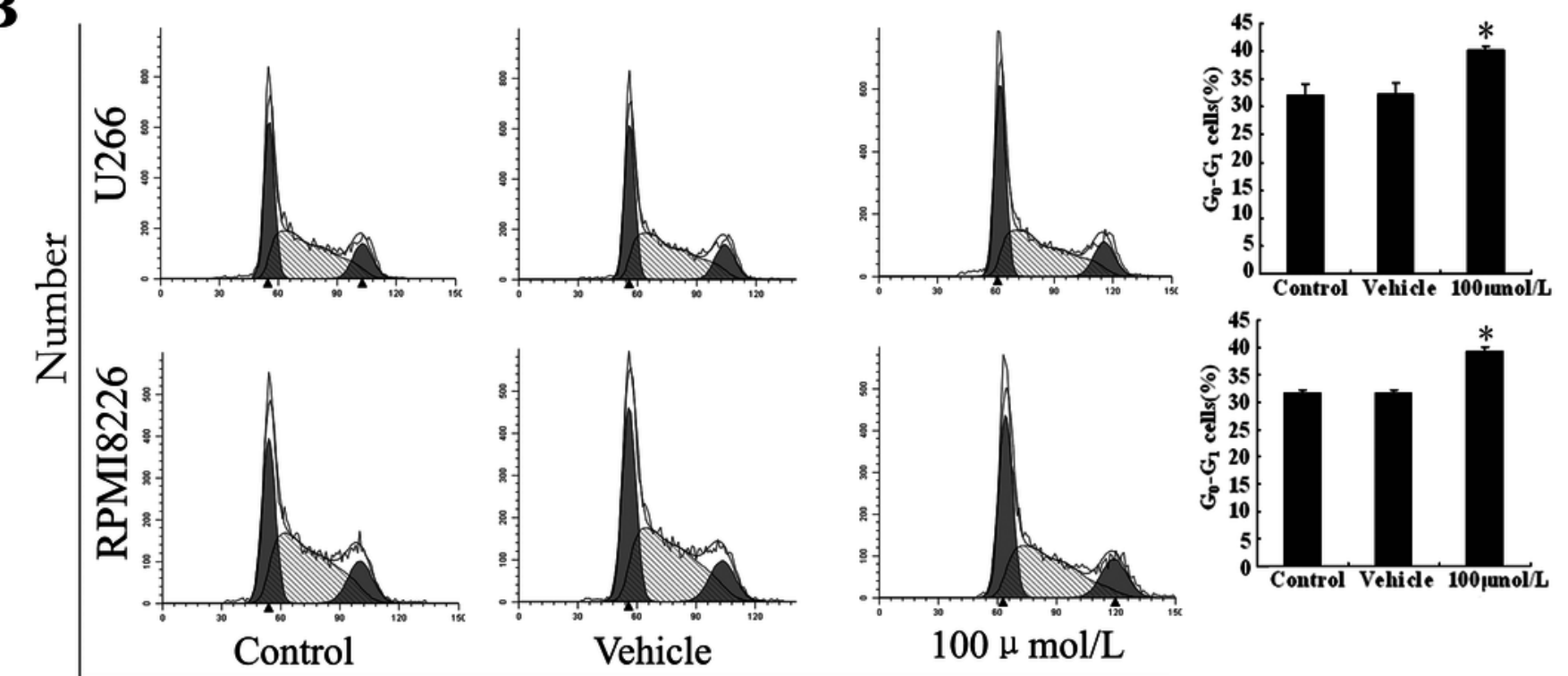
4

Effect of17-ODYA on levels of Bax, Bcl-2 and cyclin D1 protein in MM.

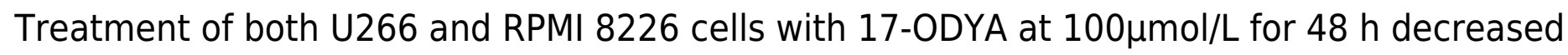
levels of cyclin $\mathrm{D} 1$, the $\mathrm{G}_{1}$ phase regulatory protein, and antiapoptotic protein $\mathrm{Bcl}-2$, while increased the level of Bax, a proapoptotic protein.

A

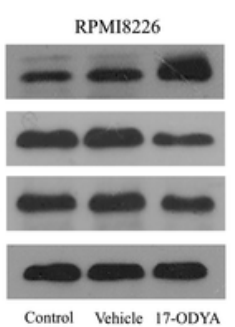

B
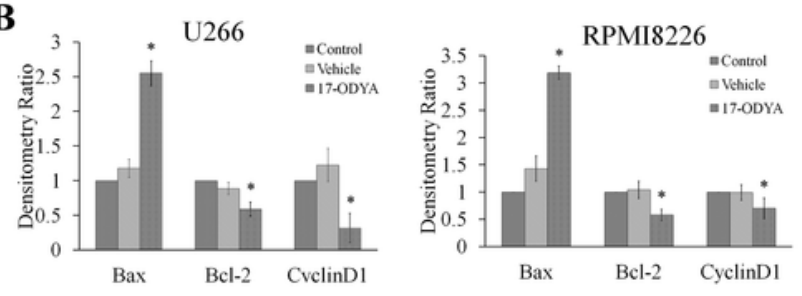


\section{5}

17-ODYA inhibits MM cell mobility through reducing MMP activity and protein levels.

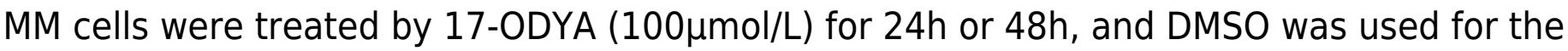
vehicle. A, 17-ODYA inhibited the migration of MM cells $\left({ }^{*} P>0.05\right.$ versus control; ${ }^{* *} P<0.05$ versus control). B, 17-ODYA inhibited the invasion of MM cells ( ${ }^{*} P>0.05$ versus control; * $P<$ 0.05 versus control). C, 17-ODYA reduced MMPs activity in the supernatant of MM cells ( $P<$ 0.05 versus control). D, 17-ODYA reduced MMPs protein level in MM cells $\left({ }^{*} P<0.05\right.$ versus control).

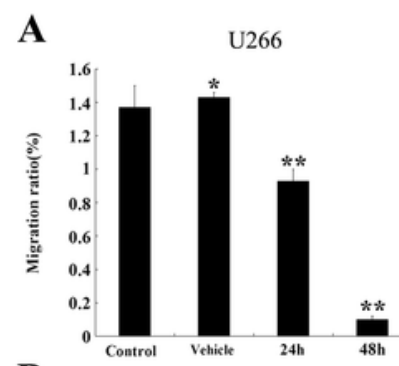

B

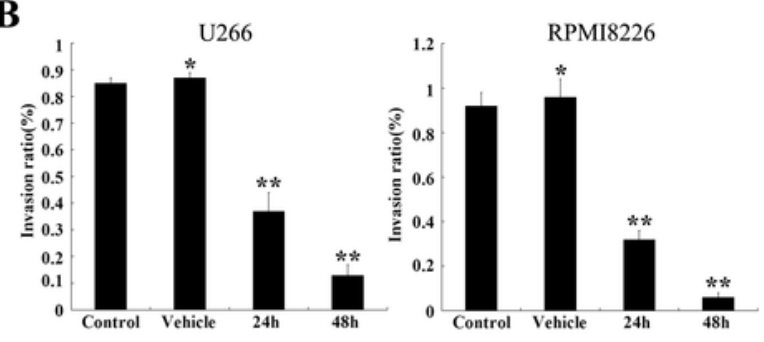

D

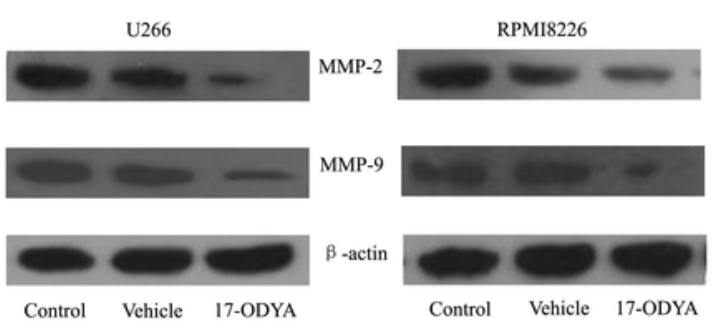

C
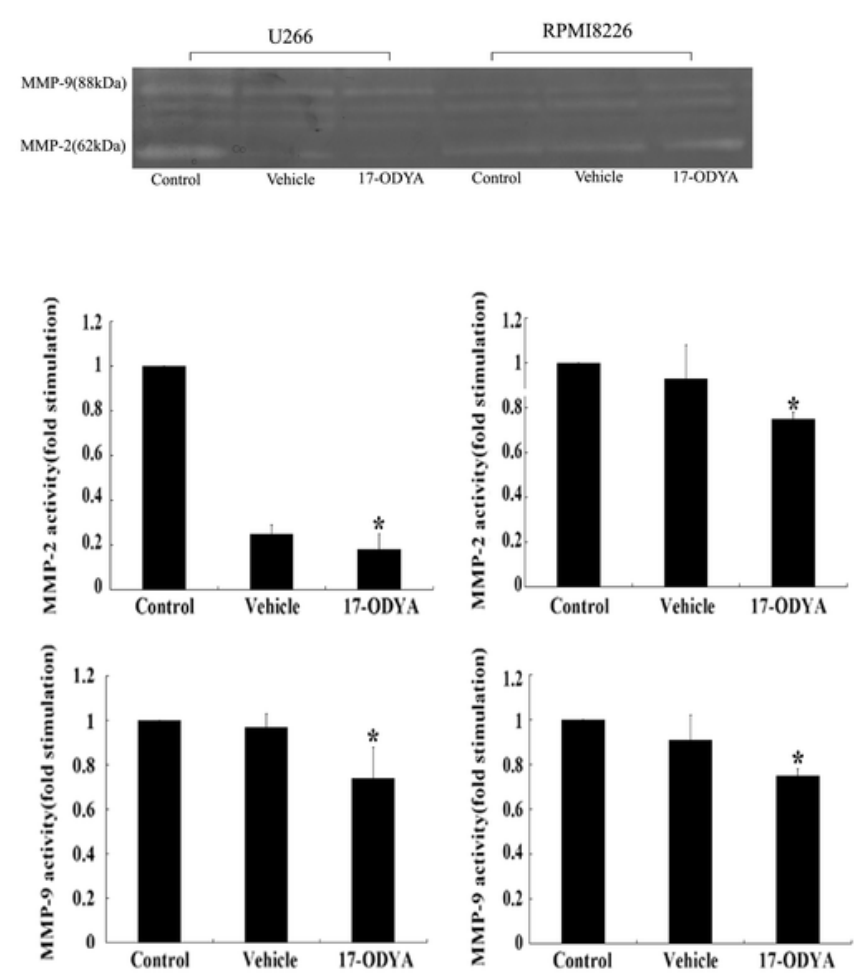


\section{Table 1 (on next page)}

Clinical features of patients with multiple myeloma. 
Table1. Clinical features of patients with multiple myeloma

\begin{tabular}{|c|c|c|c|c|c|c|}
\hline Patient no. & Age/Sex & Durie-Salmon stage & Paraprotein type & $\beta_{2}-\mathrm{M}(\mathrm{mg} / \mathrm{L})$ & LDH(U/L) & Cytogenetic feature \\
\hline 1 & $58 / \mathrm{F}$ & stageIII* & $\operatorname{IgG}, \lambda$ & 4.9 & 220 & $1 \mathrm{q} 21$ \\
\hline 2 & $48 / \mathrm{M}$ & stageIII* & $\operatorname{IgD}, \lambda$ & 18 & 164 & $14 q 32 ; 13 q 14.3 ; 1 q 21$ \\
\hline 3 & $62 / \mathrm{M}$ & stageIII* & $\operatorname{IgG}, \kappa$ & 2.9 & NA & $13 q 14.3$ \\
\hline 4 & $66 / \mathrm{M}$ & stageIII* & $\operatorname{IgD}, \lambda$ & 35.5 & 188 & Negative \\
\hline 5 & $47 / \mathrm{M}$ & stageIII & $\mathrm{BJP}, \kappa$ & 12.6 & 205 & NA \\
\hline 6 & 39/M & stageIII & $\operatorname{IgD}, \lambda$ & 4.5 & 201 & $14 q 32$ \\
\hline 7 & $60 / \mathrm{M}$ & stageIII* & $\operatorname{IgG}, \lambda$ & 15.1 & 177 & $17 \mathrm{p} 13.1$ \\
\hline 8 & $60 / \mathrm{M}$ & stage II * & $\operatorname{IgD}, \lambda$ & 3.3 & 257 & Negative \\
\hline 9 & $35 / \mathrm{M}$ & stageIII* & Nonsecreting type & 11.3 & 177 & $13 q 14$ \\
\hline 10 & $46 / \mathrm{M}$ & stageIII & $\operatorname{IgA}, \kappa$ & 3.5 & 263 & NA \\
\hline 11 & $58 / \mathrm{F}$ & stageIII & BJP, $\kappa$ & 1.3 & 200 & NA \\
\hline 12 & $60 / \mathrm{F}$ & stageIII & $\operatorname{Ig} \mathrm{A}, \lambda$ & 2.8 & NA & $14 q 32$ \\
\hline 13 & $34 / \mathrm{F}$ & stageIII* & Nonsecreting type & 9.3 & 159 & Negative \\
\hline 14 & $40 / \mathrm{M}$ & stageIII & $\operatorname{IgA}, \lambda$ & 1.5 & 234 & $17 \mathrm{p} 13.1 / 17 \mathrm{p} 11.1-\mathrm{q} 11.1$ \\
\hline 15 & $53 / \mathrm{M}$ & stageIII & $\mathrm{IgG}, \lambda$ & 1.8 & 106 & $14 q 32 ; 13 q 14$ \\
\hline 16 & $44 / \mathrm{M}$ & stageIII & BJP, $\lambda$ & 10.1 & 176 & Negative \\
\hline
\end{tabular}


Abbreviations: M, male; F, female; Ig, immunoglobulin; BJP, Bence Jones protein, $\beta_{2}-\mathrm{M}, \beta_{2}$-microglobulin; NA, not available; $*$, newly diagnosised. 